\title{
JURISPRUDENCIA CONSTITUCIONAL EN MATERIA DE PROTECCIÓN DEL MEDIO AMBIENTE
} (SEGUNDO SEMESTRE 2018)

\author{
JORDI JARIA-MANZANO \\ Profesor agregado Serra Húnter de Derecho constitucional y ambiental \\ Universitat Rovira i Virgili
}


Sumario: 1. El control sustantivo de constitucionalidad de las políticas ambientales. 2. Los límites de las facultades ejecutivas del Estado en relación con la protección del medio ambiente. 3. Un nuevo pronunciamiento sobre la fractura hidráulica: la Ley de Castilla-La Mancha.

1. EL CONTROL SUSTANTIVO DE CONSTITUCIONALIDAD DE LAS POLÍTICAS AMBIENTALES

Cincuenta diputados del Grupo Parlamentario Unidos Podemos-En Comú Podem-En Marea en el Congreso de los Diputados plantearon en su día un recurso de inconstitucionalidad contra los artículos 3 y 4 y las disposiciones adicionales primera, segunda y tercera de la Ley 2/2016, de 27 de septiembre, para la modificación de la Ley 6/2002, de 12 de junio, sobre medidas de ordenación territorial de la actividad turística en las islas de El Hierro, La Gomera y La Palma. De acuerdo con los recurrentes, la modificación legislativa constituía una vulneración del mandato constitucional de protección del medio ambiente.

Se producía, gracias a la acción de los diputados y diputadas de ese grupo parlamentario, que ya habían impugnado en su momento la Ley de la Junta General del Principado de Asturias 2/2017, de 24 de marzo, de segunda modificación de la Ley del Principado de Asturias 3/2004, de 23 de noviembre, de montes y ordenación forestal - lo que dio lugar a la STC 132/2017, de 14 de noviembre de 2017, comentada en la crónica anterior-, una nueva oportunidad para el Tribunal Constitucional de establecer los límites constitucionales sustantivos al legislador en relación con la protección del medio ambiente, cuestión que, como es sabido, ha recibido poca atención históricamente en la jurisprudencia del Juez de la Constitucionalidad. La cuestión ha venido finalmente resuelta en la Sentencia 42/2018, de 26 de abril de 2018 (BOE núm. 130, de 29 de mayo de 2018).

La Ley controvertida partía de una proposición de ley presentada por el cabildo insular de La Palma, que constataba la necesidad de promover la actividad turística en tiempos de crisis, atendiendo a la dependencia del sector que tiene el archipiélago para su desarrollo económico. De este modo, la Ley 2/2016 introducía una nueva regulación relación con el uso del suelo, destinada a promover el despliegue de la actividad turística, particularmente a través de los llamados "instrumentos de planificación singular turística", cuyo régimen excepcional tiene como consecuencia, a criterio de los recurrentes, la desactivación de las garantías de tutela ambiental contenidas en la legislación urbanística. En definitiva, se plantea la tradicional tensión entre desarrollo económico y protección del medio ambiente, desde un punto de vista sustantivo, que está en el origen de la mayor parte de conflictos de dimensión constitucional que se suscitan en materia ambiental, aunque se acaben formulando generalmente desde un punto de vista competencial.

Atendiendo a la generalidad de los motivos planteados por los recurrentes en relación con alguna de las disposiciones discutidas, lo que, de acuerdo con el 
Tribunal Constitucional, no permite situar con precisión el problema constitucional planteado, el Alto Tribunal circunscribe el litigio a "la impugnación del artículo 3, en cuanto que da nueva redacción al apartado primero del artículo 6 de la Ley 6/2002, así como sobre las disposiciones adicionales primera y segunda de la Ley $2 / 2016$, en la medida en que respecto a estas normas la demanda expone las razones en las que funda la impugnación que promueve" (FJ 2.d). A partir de aquí, el Juez de la Constitucionalidad considera que el artículo 3 no presenta razones para ser declarado inconstitucional ya que:

el precepto impugnado no contradice la legislación estatal en punto a los usos del suelo rústico. En efecto, su objeto se refiere a edificaciones ya existentes e, implícitamente, se remite a la legislación urbanística canaria al exigir que los establecimientos hoteleros a los que alude cumplan las condiciones establecidas para la respectiva categoría de suelo rústico de que se trate. Fija la regla de que la implantación de los concretos tipos de establecimiento que permite podrá realizarse «en cualquier categoría de suelo rústico», pero la condiciona a que sea posible, en función del tipo de suelo de que se trate, pues ha de cumplir «las condiciones establecidas para la respectiva categoría». Vincula así el uso turístico que se permite con el tipo de suelo de que se trate y el régimen de protección que le haya otorgado el legislador canario en el ejercicio de su competencia en materia de urbanismo. No se desconoce, por tanto, el criterio de la legislación estatal relacionado con la protección de los valores específicos de este tipo de suelo, en cuanto que el uso turístico no se permite al margen de la preservación de los posibles valores que concurran en el suelo, los cuales, como ya se ha señalado, han de ser protegidos en todo caso [FJ 4].

En cuanto a la disposición adicional primera, el Tribunal Constitucional considera, en primer lugar, que no hay contradicción con la legislación básica estatal, en la medida que

[e]n ningún caso autoriza la urbanización del suelo rústico, por cuanto la urbanización supone un proceso de transformación del suelo, de conformidad con las actuaciones previstas en el artículo 7 del Real Decreto Legislativo $7 / 2015$, que aquí no se produce. El suelo rústico continua con esa conceptuación y en ese estado sirve de soporte a la implantación de actividades turísticas en los términos de la Ley 6/2002, uno de cuyos criterios básicos de ordenación territorial es justamente ese [art. 2 b)]. Tampoco se 
excluye el respeto a las categorías de suelo fijadas por el legislador autonómico. La referencia del apartado segundo a que los instrumentos de planificación singular turística son posibles en «cualquier clase y categoría de suelo" ha de ser entendida en el sentido de que es esa previa categorización del suelo la que determina, en función del régimen de usos que se permita atendiendo al tipo de suelo de que se trate, la puesta en marcha de este tipo de instrumentos que no pueden, lógicamente, desconocer las categorías y el régimen del suelo que ha diseñado el legislador canario (art. 34, en relación con los artículos 60 a 64 de la Ley 4/2017). Por lo demás, la propia norma impugnada incorpora consideraciones medioambientales al exigir, por ejemplo, que el instrumento de planificación singular turística contenga determinaciones relativas a «la incidencia sobre el territorio físico, afecciones ambientales y medios de corrección o minimización de las mismas» y que sea sometido al correspondiente procedimiento de evaluación de impacto ambiental. Y, en fin, tampoco ha quedado demostrado que la norma, en sí misma, vaya a producir los efectos en los que los recurrentes basan su petición de declaración de inconstitucionalidad, con independencia de que la sede ordinaria del necesario control de los excesos a que la aplicación de esta norma pueda dar lugar sea la jurisdicción contencioso-administrativa (en el mismo sentido, ATC 251/2009, de 13 de octubre) [FJ 5].

El Juez de la Constitucionalidad considera, asimismo, que no se ha producido una vulneración de la autonomía local por parte de la disposición controvertida, y que, tampoco existe una vulneración del artículo 9.3 CE, en la medida que el legislador canario no asume funciones propias de la autoridad administrativa a través de la aprobación de una ley singular.

Ello, en cambio, a criterio del Tribunal, sucede con la disposición adicional segunda. Dicho precepto establecía lo siguiente:

1. Se declaran de interés insular, y quedarán, en consecuencia, exoneradas del trámite previsto en el apartado 7.b) de la Disposición adicional primera de la presente ley, las iniciativas de instrumentos de planificación singular turística que se promuevan dentro del plazo de dos años desde la entrada en vigor de la presente ley y comprendan alguna/s de las actuaciones definidas y descritas como "actuaciones específicas previstas" (AEP), "actuaciones convencionales propuestas" (ACP) o 
"actuaciones estratégicas singulares" (SDO) en las fichas contenidas en el Anexo B de la Normativa del Plan Territorial Especial de Ordenación de la Actividad Turística de la isla de La Palma, publicadas en el "Boletín Oficial de Canarias", de 10 de mayo de 2007, así como el Sistema Territorial de Equipamiento Turístico previsto en la norma 20 del mismo.

2. La declaración del interés insular contenida en el apartado anterior no exonerará, en ningún caso, de la cumplimentación de las determinaciones, documentación y evaluación medioambiental exigidas por la presente ley para los instrumentos de planificación singular turística, ni condicionará la resolución final que haya de adoptarse respecto a los mismos.

Reproduzco a continuación in extenso el razonamiento del Tribunal al respecto, en la medida que sintetiza la jurisprudencia constitucional en relación con una cuestión que, hasta el momento, se ha revelado como el iter con mayor potencialidad a la hora de controlar las decisiones del legislador que suponen una desprotección del medio ambiente, siempre en relación con proyectos específicos:

Debemos examinar, por último, si nos encontramos ante una ley singular dictada en atención a un supuesto de hecho concreto que es el que justificaría la utilización de la ley. Se trata de normas referidas a un supuesto de hecho concreto y singular, que agotan su contenido y eficacia en la adopción y ejecución de la medida tomada por el legislador ante ese supuesto de hecho, aislado en la ley singular y no comunicable con ningún otro (STC 166/1986, de 19 de diciembre, FJ 10). Una ley que no fuera de destinatario único, ni auto aplicativa, adolece de tal naturaleza si ha sido dictada en atención a un supuesto de hecho concreto, esto es, a una situación singular o excepcional (STC 129/2013, FJ 4), tal como se reconoció por este Tribunal, entre otras, en la STC 203/2013, sobre el proyecto regional "Ciudad del Medio Ambiente» de Soria, o en la STC $50 / 2015$, relativa a la modificación del plan de ordenación de los recursos naturales de Fuentes Carrionas y Fuente Cobre-Montaña Palentina (Palencia). De hecho, la intención de eludir o sortear el cumplimiento del fallo de la Sentencia dictada por el Tribunal Supremo el 18 de mayo de 2015 se configura por los demandantes como un presupuesto de la argumentación que les conduce, como consecuencia, a la denuncia de vulneración del artículo 9.3 en relación con el artículo 24.1 CE. 
Desde este último punto de vista la norma puede ser calificada como una ley singular, en cuanto que se refiere a unos concretos proyectos perfectamente identificados los cuales fueron objeto, en su momento, de regulación por el plan territorial anulado. Sobre dichas actuaciones declara que concurre el interés insular que exige la disposición adicional primera como presupuesto para poder acometer su tramitación y eventual aprobación como instrumento de planificación singular turística. Así pues, al tratarse de una ley singular de este tipo hemos de comprobar si el supuesto de hecho que contempla la norma cuestionada tiene una justificación objetiva y, de ser así, si la utilización de la ley es proporcionada a la excepcionalidad que se trata de atender y que ha justificado su aprobación (STC 170/2016, FJ 4, con cita de las SSTC 203/2013, FJ 5; 50/2015, FJ 5 y $231 / 2015, F J 3)$. A esto debe añadirse que en el caso de las leyes singulares de supuesto de hecho concreto ha de valorarse su incidencia «de forma directa, aunque no necesariamente ilegítima, en el derecho a la tutela judicial efectiva», en cuanto pueda «impedir el acceso al control judicial de derechos e intereses legítimos afectados y eliminar la posibilidad de un control judicial de la misma intensidad que hubieran podido realizar los Tribunales de la jurisdicción contencioso-administrativa» (STC 203/2013, FFJJ 3 y 8).

En cuanto a la justificación de la disposición adicional segunda, la exposición de motivos de la Ley 2/2016 no proporciona explicación alguna respecto a las razones que llevaron a su aprobación. Dicha disposición adicional segunda tiene su origen en la tramitación parlamentaria de la norma. En concreto, en una enmienda de adición presentada por dos grupos parlamentarios, enmienda que se justifica en los términos siguientes: «con el fin de posibilitar y contribuir a la implantación del modelo turístico previsto por la Ley 6/2002 y establecido por el Plan Territorial Especial de Ordenación de la Actividad Turística de la isla de La Palma, se declaran de interés insular las actuaciones incorporadas al sistema turístico planificado».

Es decir, la norma se justifica en el desarrollo de la planificación turística prevista por el legislador canario, desarrollo que, en principio y en el marco de las directrices fijadas por dicho legislador, ha de corresponder a las Administraciones competentes en la materia. La norma que ahora enjuiciamos también guarda, evidentemente, relación con lo decidido en la precitada Sentencia del Tribunal Supremo de 18 de mayo de 2015. El fallo 
judicial aprecia efectivamente la nulidad del Decreto 123/2008 y de su fundamentación se desprende que esa nulidad deriva de dos vicios de carácter procedimental: la falta de sometimiento del Decreto 123/2008 al trámite de evaluación ambiental estratégica y la vulneración de la normativa en materia de ordenación de los aeropuertos de interés general y sobre servidumbres aeronáuticas, dado que la aprobación dispensada al plan no se acomodaba a las conclusiones de sendos informes emitidos por la Dirección General de Aviación Civil. Y la misma tiene, por objeto, como ya se ha mencionado, dar por cumplimentado el trámite inicial de declaración de interés insular de determinadas actuaciones que ya fueron en su momento aprobadas por el Cabildo Insular e incluidas en el Decreto anulado, a efectos de continuar, a partir de dicha declaración, con la tramitación exigida para su aprobación como instrumentos de planificación singular turística. En suma, la norma dispensa de la declaración de interés insular por parte del Cabildo, que es el trámite al que se refiere el apartado séptimo b) de la disposición adicional primera, a determinadas actuaciones perfectamente identificadas en la misma. Declaración de interés insular que abre la vía a su tramitación y eventual aprobación como instrumentos de planificación singular turística.

Siendo ese el contenido de la norma es patente que, a diferencia de otros casos examinados por este Tribunal (SSTC 231/2015, FJ 6, o 233/2015, de 5 de noviembre, FJ 15) no hay aquí un interés de relevancia constitucional que exija inexcusablemente la aprobación de una norma con rango de ley. $\mathrm{O}$, en otros términos, la concurrencia de claras exigencias derivadas del interés general que fundamenten la medida adoptada, pues es claro que posibilitar y contribuir a la implantación del modelo turístico es una finalidad general que como tal, a partir del marco diseñado por la Ley 6/2002, puede ser asumida por las Administraciones canarias en su respectivo ámbito de competencias. Por lo demás, dicha finalidad genérica no proporciona las razones por las que serían esas concretas actuaciones mencionadas en la disposición adicional segunda y no otras distintas las que contribuirían de modo excepcional y singular a la implantación de ese modelo. Contribución que las exoneraría de la necesidad de justificar la concurrencia del interés insular en el procedimiento administrativo de elaboración del concreto instrumento de planificación singular turística. 
Y por lo que respecta a la proporcionalidad de la medida adoptada, conviene recordar el significado que hemos atribuido a este elemento del canon de constitucionalidad: «la adopción de Leyes singulares debe estar circunscrita a aquellos casos excepcionales que, por su extraordinaria trascendencia y complejidad, no son remediables por los instrumentos normales de que dispone la Administración, constreñida a actuar con sujeción al principio de legalidad, ni por los instrumentos normativos ordinarios, haciéndose por ello necesario que el legislador intervenga singularmente, al objeto exclusivo de arbitrar solución adecuada, a una situación singular» [STC 166/1986, de 19 de diciembre, FJ 11 b); doctrina reiterada en las SSTC 203/2013, FJ 8; 50/2015, FJ 7; 231/2015, FJ 6, y 233/2015, FJ 15].

La disposición que examinamos tampoco supera dicho límite. El legislador no ha explicitado las razones por las que entiende que la utilización de la ley es una medida razonable y proporcionada, teniendo en cuenta, además, que la utilización de la ley elimina el control de la jurisdicción contenciosoadministrativa en relación con la declaración de interés insular de concretas actuaciones. Actuaciones sobre las que no se ha justificado que presenten peculiaridad alguna que las diferencie de otras que también pudieran ser objeto de aprobación a través de instrumentos de planificación singular turística, siguiendo en su totalidad el procedimiento previsto en la disposición adicional primera. Atendiendo a las circunstancias del caso hay que advertir, además, que este Tribunal ya señaló que determinados vicios en los que incurre una disposición administrativa de carácter general «pueden resultar insubsanables en sí, o su subsanación puede devenir imposible, por ejemplo tras una declaración de nulidad por Sentencia firme. Entonces la Administración puede no tener otra opción, si quiere poner remedio a la infracción y perseguir la consecución del interés general concernido, que dictar un nuevo acto o un nuevo reglamento. Si el contenido de la disposición anulada es en sí mismo legal, la Administración siempre podrá volver a establecerla mediante una nueva declaración de voluntad libre de cualquier vicio procedimental, conservando incluso los trámites válidos empleados en la elaboración del declarado nulo» (STC 231/2015, FJ 4).

Finalmente cabe recordar que «en modo alguna la reserva de ley puede servir como instrumento dirigido a evitar o disminuir la protección de los derechos e intereses legítimos amparados por la legalidad ordinaria» (STC 
129/2013, FJ 5). Eso implica que, como consecuencia directa de la desproporción en que ha incurrido el legislador, la disposición adicional segunda ha vulnerado el artículo 24.1 CE, al impedir el acceso al control judicial de derechos e intereses legítimos afectados y eliminar la posibilidad de un control judicial de la misma intensidad que hubieran podido realizar los Tribunales de la jurisdicción contencioso-administrativa. Tal y como señalamos en la STC 248/2000, de 19 de octubre, FJ 5, aunque el artículo 24.1 CE «no queda vulnerado por el sólo hecho de que una materia sea regulada por norma de rango legal y, por lo tanto, resulte jurisdiccionalmente inmune», puede ocurrir que la ley resulte inconstitucional por otros motivos y se produzca, como consecuencia de ello, una vulneración del derecho reconocido en el artículo 24.1 CE: «En otras palabras: o la ley es inconstitucional por otros motivos y cierra, por serlo, ilegítimamente el paso a pretensiones que hubieran de acceder a los jueces y tribunales, $y$, en este caso, puede vulnerar de forma derivada el derecho reconocido en el artículo 24.1 CE (STC 181/2000, FJ 20); o la ley es conforme a la Constitución y, en tal supuesto, pertenece a su propia naturaleza de ley el no poder ser enjuiciada por los jueces y tribunales ordinarios» (en un sentido similar, STC 203/2013, FJ 8).

En definitiva, el Tribunal resume con estas palabras su doctrina en relación con las leyes singulares, en la medida que constituyen un uso ilegítimo de la potestad legislativa que se traduce en una falta de garantías para los justiciables, que gozarían de vías de impugnación en el caso que la medida tomada legislativamente se hubiera adoptado por parte de la Administración, siendo que uso de la ley no es razonable ni proporcionado en el caso concreto.

\section{LOS LÍMITES DE LAS FACULTADES EJECUTIVAS DEL ESTADO EN RELACIÓN CON LA PROTECCIÓN DEL MEDIO AMBIENTE}

El Gobierno de la Generalitat de Cataluña planteó un conflicto positivo de en relación con diversos preceptos del Real Decreto 635/2013, de 2 de agosto, por el que, en desarrollo del "Plan de Impulso al Medio Ambiente en el sector hotelero PIMA Sol" para la rehabilitación energética de sus instalaciones, se regula la adquisición de créditos futuros de carbono por el fondo de carbono para una economía sostenible. De acuerdo con la representación procesal del Gobierno 
de Cataluña no se discute la regulación sustantiva contenida en el Real Decreto controvertido, sino el hecho que "en dicha regulación, para la aplicación del sistema de ayudas en relación con la evaluación y compra de derechos de $\mathrm{CO}_{2}$ dentro del Plan 'PIMA Sol' se margina nuevamente a las Comunidades Autónomas de las funciones ejecutivas que en materia de medio ambiente, relacionado en este caso con el sector turístico, les corresponde ejercer". La cuestión ha sido resuelta mediante la Sentencia 62/2018, de 7 de junio (BOE núm. 164, de 7 de julio de 2018)

El Tribunal Constitucional considera, por su parte, que "el Real Decreto 635/2013 comparte en sus aspectos esenciales el contexto normativo, el objeto y la finalidad del Real Decreto 1494/2011 por el que se regula el fondo de carbono para una economía sostenible, se llega necesariamente a la misma conclusión que se alcanzó en la STC 15/2018 en relación con su encuadramiento competencial, a cuyos fundamentos jurídicos 4 y 5 basta ahora con remitirse para evitar reiteraciones innecesarias" (FJ 3) ${ }^{1}$. Dicho esto, el Juez de la Constitucionalidad considera que "la cuestión que debe resolverse en este conflicto es si puede el Estado asumir, en el marco de las competencias que le atribuyen el apartado vigésimo tercero del artículo 149.1 CE, las funciones ejecutivas que establece el Real Decreto 635/2013 en relación con la tramitación de las solicitudes, valoración y adquisición de créditos de carbono en desarrollo del «Plan de Impulso al Medio Ambiente en el sector hotelero el marco del Programa PIMA Sol». O si, por el contrario, vulneran el orden constitucional y estatutario de distribución de competencias al no concurrir ninguna de las circunstancias que puedan justificar la excepcionalidad determinante de la atribución al Estado de dichas facultades" (FJ 4).

Una vez enmarcado el contencioso en estos términos, el Alto Tribunal subraya las diferencias entre el supuesto resuelto en la STC 15/2018, de 22 de febrero, que definía la doctrina aplicable al caso, y el presente conflicto. Así, según el Tribunal, existen "sustanciales diferencias entre el régimen de adquisición de créditos de carbono establecido por el Real Decreto 635/2013, por una parte, y el régimen general establecido por el Real Decreto 1494/2011, por otra, y que

\footnotetext{
${ }^{1}$ La Sentencia citada fue comentada en la crónica correspondiente al primer semestre del año en curso.
} 
fue objeto de la STC 15/2018, en relación con la justificación de una ejecución centralizada: mientras que el Real Decreto 1494/2011 establece en su artículo 7.4 unos criterios generales que enmarcan el amplio margen de discrecionalidad reconocido a los órganos del fondo a la hora de priorizar los sectores y actuaciones en relación con los cuales se pueden adquirir estos créditos, y que requieren un análisis de conjunto de todos los proyectos presentados en sectores diversos a la luz de dichos criterios, no ocurre igual en el caso del Real Decreto 635/2013, en el que el sector está ya delimitado y se predeterminan en gran medida los proyectos y actuaciones para la reducción de emisiones $\mathrm{CO}_{2}$ que puedan reconocerse como créditos de carbono" (FJ 6).

En relación con ello, el Juez de la Constitucionalidad despliega la clave de su razonamiento, de acuerdo con la cual no se dan los supuestos excepcionales que permiten la ampliación de la competencia en materia de legislación básica sobre protección del medio ambiente hasta los actos de ejecución. Ello conlleva la estimación parcial de las demandas del Gobierno de la Generalitat, aparte de proporcionar una delimitación de las competencias del Estado en esta materia que, en los últimos tiempos, habían sido interpretadas con una notable amplitud por parte del Tribunal Constitucional.

Un supuesto paralelo es el que resuelve la Sentencia $64 / 2018$, de 7 de junio (BOE núm. 164, de 7 de julio de 2018). Nuevamente, el Gobierno de la Generalitat discute la adecuación de una norma estatal al orden constitucional de competencias, en este caso, se trata de diversos preceptos del Real Decreto 1007/2015, de 6 de noviembre, por el que se regula la adquisición por el fondo de carbono para una economía sostenible, de créditos de carbono del plan de impulso al medio ambiente en el sector de la empresa "PIMA Empresa" para la reducción de gases de efecto invernadero en sus instalaciones. Nuevamente, el caso es encuadrado de acuerdo con lo dispuesto por el Tribunal en la ya mencionada STC 15/2018, de 22 de febrero.

Como en el caso resuelto en la Sentencia comentada anteriormente en este mismo epígrafe, el Tribunal Constitucional considera que:

[se dan] sustanciales diferencias entre el régimen de adquisición de créditos de carbono establecido por el Real Decreto 1007/2015, y el establecido por el Real Decreto 1494/2011, objeto de la STC 15/2018, en relación con la 
justificación de una ejecución centralizada: mientras que el Real Decreto 1494/2011 establece unos criterios generales que enmarcan el amplio margen de discrecionalidad reconocido a los órganos del fondo a la hora de priorizar los sectores y actuaciones en relación con los cuales se puede adquirir estos créditos, y que requieren un análisis de conjunto de todos los proyectos presentados en sectores diversos a la luz de dichos criterios, no ocurre igual en el caso del Real Decreto 1007/2015, en el que su ámbito de aplicación está ya predeterminado a las empresas que estén inscritas en el registro regulado por el Real Decreto 163/2014, de 14 de marzo, por el que se crea el registro de huella de carbono, y se delimita en gran medida los proyectos y actuaciones para la reducción de emisiones $\mathrm{CO}_{2}$ que puedan reconocerse como créditos de carbono [FJ 6].

Por ello, de acuerdo con el Tribunal Constitucional, "en este caso no concurren los requisitos que, con carácter excepcional, pueden justificar que el Estado se reserve tales competencias de ejecución" (FJ 6), lo que conlleva una estimación parcial, en términos bastante amplios, de las pretensiones del Gobierno de Cataluña, de modo que, como en la Sentencia anteriormente comentada, se despliega una doctrina que contribuye a delimitar las competencias ejecutivas excepcionales del Estado en relación con el art. 149.1.23 CE.

Finalmente, en relación con el tema que nos ocupa, debe mencionarse aquí también la Sentencia 88/2018, de 19 de julio (BOE núm. 199, de 17 de agosto de 2018), relativa al conflicto de competencias planteado, nuevamente, por el Gobierno de Cataluña en relación con diversos preceptos del Real Decreto 264/2017, de 17 de marzo, por el que se establecen las bases reguladoras para la financiación de la adaptación de las líneas eléctricas de alta tensión a los requisitos establecidos en el Real Decreto 1432/2008, de 29 de agosto, por el que se establecen medidas para la protección de la avifauna contra la colisión y la electrocución en líneas eléctricas de alta tensión.

En este caso, se produce también una estimación parcial de las pretensiones de la institución recurrente, subrayando de nuevo los límites en los que deben desplegarse las atribuciones ejecutivas excepcionales que derivan del artículo 149.1.23 CE. Consiguientemente, se produce una declaración de inconstitucionalidad de la mayoría de los preceptos controvertidos, en la medida que atribuyen a la Administración del Estado "funciones de naturaleza ejecutiva 
que contravienen el orden constitucional de distribución de competencias" (FJ 7).

\section{UN NUEVO PRONUNCIAMIENTO SOBRE LA FRACTURA HIDRÁULICA: LA LEY DE CASTILLA-LA MANCHA}

La intervención de las comunidades autónomas en relación con la fractura hidráulica, que ha comportado diferentes modalidades de prohibición, ha suscitado una serie de pronunciamientos del Tribunal Constitucional a lo largo de los últimos años. El último de ellos es el que se refiere a la Ley de las Cortes de Castilla-La Mancha 1/2017, de 9 de marzo, por la que se establecen medidas adicionales de protección de la salud pública y del medio ambiente para la exploración, investigación o explotación de hidrocarburos utilizando la técnica de la fractura hidráulica, impugnada, como en los casos anteriores, ya comentados en crónicas previas, por el Presidente del Gobierno.

En este caso, aparte de un par de disposiciones transitorias y una final, el conflicto constitucional se centraba en el artículo 3 de la Ley, cuyo tenor literal es el siguiente.

1. La consejería competente en materia de medio ambiente elaborará en coordinación con las consejerías que ostenten competencias de salud pública, energía y ordenación del territorio, un plan estratégico de la utilización de la fractura hidráulica en Castilla-La Mancha (en adelante, plan estratégico) para prevenir, gestionar y reducir los impactos y los riesgos para la salud pública y el medio ambiente derivados de esta técnica en su territorio, que deberá ser aprobado por el Consejo de Gobierno mediante decreto a la mayor brevedad, en todo caso en el plazo máximo de dieciocho meses.

2. En la elaboración del plan estratégico se contará obligatoriamente desde el principio con la participación de la población afectada, de conformidad con lo estipulado en la Ley 27/2006, de 18 de julio, por la que se regulan los derechos de acceso a la información, de participación pública y de acceso a la justicia en materia de medio ambiente, así como en su evaluación ambiental. No obstante, en ambos supuestos resultará, además, 
preceptivo el trámite de información pública e informe del Consejo Asesor de Medio Ambiente.

3. El plan estratégico será objeto de evaluación ambiental estratégica en los términos marcados por la de 9 de diciembre, de evaluación ambiental, y su legislación de desarrollo. En esta evaluación ambiental se deberán analizar con especial atención los riesgos derivados de la técnica sobre la salud humana y el medio ambiente, las necesidades de recursos hídricos, la gestión de los residuos generados, la gestión de todas las aguas de operación y los vertidos, y las emisiones de contaminantes atmosféricos y de gases de efecto invernadero.

4. El plan estratégico incluirá un informe de la Oficina de Cambio Climático de Castilla-La Mancha que informe y analice el impacto de dicho plan sobre la consecución de los objetivos establecidos en la Estrategia Regional de mitigación y adaptación frente al cambio climático.

5. El plan estratégico deberá contener las siguientes determinaciones:

a) La adecuada evaluación de riesgos a escala regional que permita valorar las posibilidades de fugas o migraciones de fluidos de perforación, fluidos de fractura hidráulica, material en estado natural, hidrocarburos y gases desde los pozos o las formaciones geológicas objetivo a las aguas superficiales o subterráneas, así como la sismicidad inducida que pudiera generarse y los posibles efectos de inestabilidad geológica.

b) Una zonificación del territorio que diferencie las zonas donde quede restringida la técnica de la fractura hidráulica, con el fin de dar protección a la salud humana y la biodiversidad, por los riesgos para la contaminación de las aguas superficiales y subterráneas, por la naturaleza de la potencial sismicidad inducida, para evitar afecciones sobre las áreas y recursos naturales protegidos, para evitar impactos sobre el patrimonio cultural, así como por una afección relevante sobre el resto de elementos geológicos, ambientales, paisajísticos o socioeconómicos.

c) Esta zonificación incluirá el establecimiento de las distancias mínimas de protección que deberán guardarse entre las zonas aptas para la aplicación de la fractura hidráulica y sus zonas de exclusión, así como limitaciones en relación con la distancia mínima en profundidad entre la zona del subsuelo que va a fracturarse y cualquier masa de agua subterránea. Asimismo, con el objeto de prevenir un aumento de sedimentos en las aguas 
superficiales que se produce cuando existe una alta densidad de pozos se deberán establecer distancias mínimas de los pozos a los cuerpos de agua superficial.

En relación con los pronunciamientos anteriores en relación con esta materia, el Tribunal Constitucional señala que

[a] diferencia entonces de las leyes autonómicas enjuiciadas hasta la fecha por el Tribunal en esta serie sobre el fracking, este artículo 3 de la Ley de Castilla-La Mancha 1/2017 (i) ni contiene una prohibición legal expresa de esta técnica de carácter absoluto e incondicionado como en los casos de las SSTC 106/2014, 134/2014, y 208/2014. (ii) Ni efectúa tampoco una remisión incondicionada o en blanco a la Administración para que regule su posible uso (reformas de las leyes del suelo de Cataluña y País Vasco declaradas inconstitucionales en las SSTC 73/2016 y 8/2018). (iii) Tampoco contiene, en fin, una medida singular en relación con determinados acuíferos como en el caso de la reforma de la Ley de aguas del País Vasco declarada constitucional en la STC 8/2018, FJ 4 b).

Este artículo 3 contiene en definitiva una norma novedosa y no examinada hasta la fecha, consistente en habilitar a la Administración autonómica para que esta efectúe una «zonificación» del territorio de la Comunidad Autónoma y delimite áreas donde la técnica del fracking quede excluida, restringida o permitida en atención a los criterios que la ley señala y que, a diferencia de lo acontecido en las reformas de las leyes del suelo de Cataluña y País Vasco anuladas en las antes aludidas SSTC 73/2016 y 8/2018, no incluyen una referencia final a cualquier ámbito competencial de la Comunidad Autónoma [FJ 4].

El hecho de que no se trate de una prohibición general, sino que la norma se limite a prever una zonificación de acuerdo con la cual pueda valorarse la idoneidad del uso de esta técnica de extracción de hidrocarburos es determinante a la hora de configurar el pronunciamiento del Tribunal Constitucional, que no concluye en una declaración de inconstitucionalidad, como en casos anteriores, ya que, en definitiva, de acuerdo con su razonamiento, la comunidad autónoma ejerce, en este caso, sus competencias en materia de protección del medio ambiente y ordenación del territorio de manera legítima, en la medida que se admite que "desde uno u otro título - 
ordenación del territorio, competencia exclusiva, o medio ambiente, competencia de desarrollo de las bases estatales y de ejecución- la Comunidad Autónoma puede crear un instrumento normativo como el «plan estratégico de la utilización de la fractura hidráulica» de este artículo 3" (FJ 8).

A partir de ahí, el Alto Tribunal concluye que:

Evidentemente, y atendido el estricto objeto de este proceso, no procede evaluar aquí la adecuación del plan aun no aprobado ni objeto de este proceso con la citada doctrina constitucional. Procede en cambio declarar, de acuerdo con todo lo anterior, que la simple previsión de un «plan estratégico de la utilización de la fractura hidráulica» que debe aprobar el Gobierno autonómico contenida en el artículo 3 de la Ley de Castilla-La Mancha 1/2017, no puede considerarse contraria al orden constitucional de distribución de competencias.

De este modo, el Tribunal preserva la norma legislativa autonómica, en la medida que no existe una contradicción actual con el sistema constitucional de distribución de competencias. Otra cosa será lo que pueda decir una vez el plan aludido en la norma controvertida se apruebe, por lo que, seguramente, cabe pensar que el serial de la fractura hidráulica ante la jurisdicción constitucional todavía no ha terminado. 